\title{
CICLOS DA TRAJETÓRIA PROFISSIONAL NA CARREIRA DOCENTE EM EDUCAÇÃO FÍSICA
}

\author{
CYCLES OF PROFESSIONAL TRAJECTORY IN PHYSICAL EDUCATION \\ TEACHING CAREER
}

\section{CICLOS DE LA TRAYECTORIA PROFESIONAL EN LA CARRERA DOCENTE EN EDUCACIÓN FÍSICA}

\author{
Gelcemar Oliveira Farias*, Paula Maria Fazendeiro Batista**, Amândio Graça**, \\ Juarez Vieira do Nascimento***
}

Palavras chave:

Mobilidade

profissional.

Educação Física

e treinamento.

Socialização.

\begin{abstract}
Resumo: 0 objetivo desta investigação foi analisar a carreira de professores de Educação Física, considerando os ciclos da trajetória profissional docente. Participaram do estudo descritivo-exploratório bietápico 64 professores de Educação Física atuantes em escolas municipais de Porto Alegre/RS. No primeiro momento foram aplicados questionários $(n=64)$ e no segundo momento realizadas entrevistas semiestruturadas $(n=13)$. Os resultados possibilitaram a identificação de cinco ciclos que caracterizam a carreira docente dos professores de Educação Física, nomeadamente a Entrada na Carreira, Consolidação das Competências Profissionais na Carreira, Afirmação e Diversificação na Carreira, Renovação na Carreira e Maturidade na Carreira. A continuação dos estudos é sugerida para acompanhar docentes após o processo de aposentadoria, bem como ampliar a caracterização dos diferentes ciclos da carreira de professores de Educação Física.
\end{abstract}

Keywords: Career Mobility. Physical Education and Training.

Socialization

\begin{abstract}
This investigation looked into the career of the Physical Education teachers, considering the cycles of their professional trajectories. Sixty-two Physical Education teachers working in municipal schools in Porto Alegre, RS, participated in the descriptiveexploratory two-stage study. First, questionnaires were applied $(n=64)$ and then semistructured interviews $(n=13)$ were conducted. Besides, it was possible to identify the cycles that characterize the educational career of Physical Education teachers, which are: entrance; consolidation of professional competences; affirmation and diversification; renewal; and maturity. More studies are suggested for following teachers after they retire as well as to broaden the characterization of the different career cycles of Physical Education teachers.
\end{abstract}

Resumen: El objetivo de esta investigación fue analizar la carrera de profesores de Educación Física, considerando los ciclos de su trayectoria profesional docente. Participaron del estudio descriptivo exploratorio bietápico 64 profesores de Educación Física que actúan en escuelas municipales de Porto Alegre, Rio Grande do Sul. En el Movilidad Laboral. Educación y Entrenamiento Físico. Socialización. primer momento se aplicaron cuestionarios $(n=64)$ y en el segundo momento se realizaron entrevistas semiestructuradas $(n=13)$. Los resultados posibilitaron la identificación de cinco ciclos que caracterizan la carrera docente de los profesores de Educación Física, que son: Entrada en la Carrera, Consolidación de las Competencias Profesionales en la Carrera, Consolidación y Diversificación en la Carrera, Renovación en la Carrera y Madurez en la Carrera. La continuación de los estudios se sugiere para acompañar a los docentes después del proceso de jubilación, así como ampliar la caracterización de los diferentes ciclos de la carrera de los profesores de Educación Física.
*Universidade do Estado de Santa Catarina. Florianópolis, SC, Brasil. E-mail: fariasgel@ hotmail.com; juarez.nascimento@ufsc.br

**Universidade do Porto, Porto, Portugal.

E-mail: paulabatista@fade.up.pt; agraca@ fade.up.pt

***Universidade Federal de Santa Catarina. Florianópolis, SC, Brasil. E-mail: juarez.nascimento@ufsc.br

Recebido em: 17-07-2017 Aprovado em: 07-12-2017

$\mathrm{DOl}$ http://dx.doi.org/10.22456/1982-8918.75045 (c) (1) (8) Licence 


\section{INTRODUÇÃOO}

Os estudos centrados na carreira docente têm revelado que esta pode ser compreendida a partir do processo de socialização profissional (STROOT, 1996; TARDIF, 2000; VALLE, 2006), e que é regulada por uma sucessão de fatos e acontecimentos que se tornam marcantes na trajetória do professor (GONÇALVES, 2000; 2009; HUBERMAN, 2000; NASCIMENTO; GRAÇA, 1998; STEFFY et al., 2000). Além disso, a carreira resulta dos acordos entre indivíduos e as ocupações (TARDIF; RAYMOND, 2000), os quais tendem a ser percebidos quando o docente adquire competências, busca e mescla diferentes fontes de conhecimentos para atualização profissional, assimila saberes docentes indispensáveis para o desenvolvimento da sua prática pedagógica e delibera crenças e expectativas que podem ou não ser alcançadas durante a evolução profissional.

$\mathrm{Na}$ literatura consultada sobre a aderência à carreira docente, algumas investigações têm reportado elementos da socialização antecipatória, mais especificamente nos fatores pertinentes à entrada na escola ou no ensino superior (BERSON; BREAULT, 2000; BOTH, 2016; CORSI, 2006; DÍAZ, 2005; FARIAS et al., 2016; FREIRE; FERNANDEZ, 2015; FREITAS, 2002; ILHA; KRUG, 2016; LENGERT, 2005; MONTEIRO; MIZUKAMI, 2002). Além disso, outros estudos têm contemplado os fatores relacionados com a saída da carreira (DAGENAIS; STEFFY; ENZ, 2000; FOLLE; NASCIMENTO, 2009; HOPF, CANFIELD, 2001; HOPF, 2002; SANTOS; BRACHT; ALMEIDA, 2009; VEIGA et al., 2007).

Ao caracterizarem os diferentes ciclos ou estágios da carreira de professores, Huberman (2000) e Gonçalves (2000; 2009) verificaram que os docentes vivenciam momentos distintos na entrada da carreira. Enquanto que Huberman (2000) destaca as fases que caracterizam a descoberta e choque com a realidade, Gonçalves (2000; 2009) descreve as fases de sobrevivência e descoberta. De fato, os primeiros anos de intervenção profissional trazem implicações significativas à carreira do professor, as quais podem ser referência para o êxito ou insucesso profissional. As investigações sobre o professor no final da carreira docente têm demonstrado como ele revê e/ou observa a sua vida profissional (ANACLETO; CELY, 2016; FOLLE; NASCIMENTO, 2009; FREITAS, 2002; HOFP, 2002). Ao analisarem os professores próximos da fase de aposentadoria, Folle e Nascimento (2009) identificaram que os acontecimentos ocorridos no período de entrada na carreira compreenderam os piores momentos da atuação profissional, enquanto que os melhores momentos foram registrados por sucessivos acontecimentos ocorridos ao longo da carreira docente.

Na tentativa de melhor compreender como os professores se desenvolvem profissional e pessoalmente, algumas investigações procuraram elucidar os ciclos ou estágios da carreira docente de professores (ANACLETO; CELY, 2016; BARONE et al., 1996; FEIMANNEMSER, 1982; GONÇALVES, 2000; 2009; HUBERMAN, 2000; NASCIMENTO; GRAÇA, 1998; RODRIGUES, 1987; STEFFY et al., 2000; STROOT, 1996). Apesar das investigações identificarem diferentes momentos perceptíveis da carreira docente, há uma escassez de estudos que abordem a carreira docente como um todo, principalmente dos professores de Educação Física. Nesta perspectiva, o objetivo do presente estudo foi analisar a carreira dos professores de Educação Física, considerando os ciclos da trajetória profissional docente. O desafio da investigação foi a construção de um modelo teórico que possa identificar e caracterizar os diferentes ciclos ou estágios da carreira docente de professores de Educação Física, atuantes no magistério público municipal de Porto Alegre/RS. 


\section{MÉTODO}

A investigação caracterizou-se como um estudo descritivo, bietápico, de caráter exploratório. No primeiro momento da investigação participaram 64 professores de Educação Física vinculados à Secretaria Municipal de Educação de Porto Alegre, que foram convidados a participar voluntariamente da pesquisa, a partir dos seguintes critérios de inclusão: professores com formação inicial em Educação Física e efetivos da rede municipal de ensino de Porto Alegre; atuantes no ensino fundamental ou atuantes em cargos administrativos (gestores) na escola; e professores que atuam em outras redes de ensino, desde que efetivos na Secretaria Municipal de Educação. Professores afastados das atividades docentes (licenças, qualificação profissional, entre outros) não fizeram parte do estudo.

Embora todos os professores sejam graduados em Educação Física, alguns $(15,6 \%)$ também realizaram formação inicial em outras áreas de conhecimento (Ciências Humanas e da Saúde). A maioria dos professores era do sexo feminino $(51,5 \%)$ e da faixa etária de 30 a 49 anos (75,7\%). A formação em nível de pós-graduação foi um fator de destaque entre os professores investigados, pois 45 (70,3\%) eram especialistas nas áreas de Educação Física Escolar, Educação Inclusiva, Pedagogia do Esporte, Educação Psicomotora, Medicina Esportiva, Recreação e Lazer e Saúde mental, e 13 (20,3\%) estavam em formação ou já possuíam o título de mestre ou doutor na área da Educação. Em relação à atuação profissional no contexto da docência em Educação Física, encontraram-se professores com um ano até 38 anos de docência. A maioria dos professores possuía de sete a 19 anos (32,8\%) e 20 anos ou mais $(59,3 \%)$ de docência em Educação Física.

No segundo momento da investigação, o qual teve o intuito de aprofundar as informações coletadas na primeira etapa, participaram 13 professores de Educação Física que atendiam aos seguintes critérios: pelo menos, quatro professores de cada ciclo de desenvolvimento profissional proposto por Nascimento e Graça (1998); professores que se encontravam em diferentes momentos da carreira (início, meio e final); pelo menos, dois professores do gênero masculino e dois professores do gênero feminino em cada ciclo; pelo menos, dois professores graduados/especialistas e dois professores mestres/doutores em cada ciclo de desenvolvimento profissional; pelo menos, um professor que atua em uma única escola e um professor que atua em mais de uma escola ou outro contexto em cada ciclo de desenvolvimento profissional. Os 13 professores investigados possuíam graduação e especialização em Educação Física, sendo que quatro $(30,8 \%)$ eram mestres ou doutores. Além disso, um $(7,6 \%)$ estava na entrada da carreira (até três anos de docência), quatro $(30,8 \%)$ na consolidação da carreira (quatro a seis anos de docência), quatro (30,8\%) na diversificação da carreira (sete a 19 anos) e quatro $(30,8 \%)$ na estabilização da carreira (20 anos ou mais) de acordo Nascimento e Graça (1998).

Para a coleta de dados no primeiro momento foi construído e validado um questionário, cuja matriz contemplou as dimensões dados de identificação, características profissionais, características pessoais, socialização profissional, profissionalidade e condições de vida no trabalho docente. Já para a recolha de informação no segundo momento foi aplicada uma entrevista semiestruturada, organizada a partir de temas geradores (a formação inicial em Educação Física; o início da carreira docente; relação com os pares; características profissionais; características pessoais; condições de trabalho; trabalho e espaço total da vida; como a sua trajetória profissional seria resumida) que resultaram da análise das informações coletadas no 
momento anterior. Os procedimentos de recolha dos dados ocorreram no ambiente de trabalho de cada professor, em dia e hora de sua conveniência, possibilitando a criação de uma relação de confiança entre o investigador e os professores, ampliando a veracidade das informações colhidas (CÔTÉ et al., 1993).

A coleta de dados foi realizada após a aprovação do projeto pelo Comitê de Ética em Pesquisa com Seres Humanos da Universidade Federal de Santa Catarina (088 FR- 249158). A participação dos professores na investigação foi efetivada a partir da assinatura do Termo de Consentimento Livre Esclarecido, o qual continha as informações quanto ao objetivo do estudo, a inserção e desistência, os riscos e os desconfortos resultantes da participação no estudo.

As informações coletadas foram inseridas e categorizadas no Software Nvivo 7 (QSR Nvivo), o qual compreende uma importante ferramenta que auxilia o pesquisador na organização e sistematização de dados qualitativos (BATISTA, 2008; GRBICH, 2013). Embora algumas categorias de análise tenham sido estabelecidas a priori, as demais categorias emergiram do conteúdo analisado. A Análise do Conteúdo (BARDIN, 2009), considerando as etapas préanálise, exploração do material e tratamento dos resultados, inferência e interpretação, foi realizada após terem sido tomados todos os cuidados metodológicos. Além da credibilidade descritiva dos dados a partir da checagem pelos participantes, a interpretação dos dados foi checada por investigadores especialistas na área (SPARKES; SMITH, 2014).

\section{RESULTADOS}

A opção neste estudo pela terminologia ciclos é justificada por entender que a carreira pode ser caracterizada por sucessivos momentos, os quais se articulam na elaboração de um constructo de conhecimentos, crenças, perspectivas e experiências originadas na atuação profissional propriamente dita. As evidências encontradas na investigação, resultantes dos dados coletados na primeira e na segunda etapa do estudo, possibilitaram a identificação de cinco ciclos que caracterizam a carreira docente de professores de Educação Física, quais sejam: Entrada na Carreira; Consolidação das Competências Profissionais na Carreira; Afirmação e Diversificação na Carreira; Renovação na Carreira; Maturidade.

\subsection{Ciclo de entrada na carreira}

O Ciclo de Entrada na Carreira compreende os primeiros anos da carreira docente, nomeadamente os professores que atuam de um a três anos de docência (HUBERMAN, 2000; NASCIMENTO; GRAÇA, 1998) ou de um a quatro anos (GONÇALVES, 2000; 2009), sendo representado no estudo por três professores de Educação Física. Neste estudo, considerando o número de participantes e as similaridades das informações concebidas pelos professores de Educação Física, o Ciclo de Entrada na Carreira compreendeu os professores com até quatro anos de docência, os quais apresentaram idades de 27 e 28 anos. Uma particularidade dos professores pertencentes a este ciclo é a formação continuada (pós-graduação lato e stricto sensu), a qual foi realizada por todos professores investigados.

Os professores de Educação Física, neste momento, apresentam uma estreita relação com a formação inicial, frequentemente remetem-se aos conhecimentos adquiridos para justificar a sua prática pedagógica no contexto escolar, conforme evidenciado no estudo de 
Henrique e Costa (2016). As experiências vivenciadas nos estágios curriculares e nos projetos de extensão universitária também constituíram uma base sólida de conhecimentos que se tornou preponderante à atuação no início da carreira profissional, resultando em aumento da motivação inicial para o exercício profissional, o que também foi encontrado na investigação de Steffy et al. (2000) com professores novatos na carreira.

Um fato a ser destacado no Ciclo de Entrada na Carreira está relacionado à aquisição de competências dos professores de Educação Física. As restritas experiências profissionais possibilitaram a efetivação de competências relacionadas ao conhecimento tácito, além das competências oriundas da associação entre o conhecimento teórico adquirido na formação inicial e o conhecimento formal da profissão (CHEETHAM; CHIVERS, 1998; BATISTA, 2008).

As histórias e memórias de sucesso neste momento da trajetória profissional são destacadas por Hebert e Worthy (2001) e Henrique e Costa (2016), quando apontam que a socialização antecipatória, as experiências da formação inicial e esportivas e as características do contexto de trabalho de professores principiantes podem configurar indicativos para uma permanência prolongada na carreira docente e o sucesso em períodos subsequentes. Enquanto que Huberman (2000) revela que o período de entrada é marcado pelas fases de choque com a realidade e de descoberta, Gonçalves (2000) descreve que o professor experimenta as fases de sobrevivência e a descoberta.

Assim, neste estudo foram encontradas duas fases distintas neste ciclo, a fase de choque com a realidade e a fase de tomada de decisão. Enquanto a fase de choque com a realidade foi expressa quando os docentes mencionaram os conflitos entre os estudantes que geram atritos físicos, as dificuldades do contexto de trabalho sem perspectivas de mudanças sociais, bem como a falta de apoio para o desenvolvimento das ações docentes, a fase de tomada de decisão é configurada pela motivação e entusiasmo pela docência, marcada pela perspectiva de continuidade na carreira, de mudanças das estratégias pedagógicas para a melhoria da qualidade de suas aulas.

\subsection{Ciclo de consolidação das competências profissionais na carreira}

Este ciclo da trajetória docente compreendeu seis professores investigados que atuam de cinco a nove anos e possuem idades entre 30 a 41 anos. 0 Ciclo de Consolidação das Competências Profissionais na Carreira foi assim denominado pelo fato de que os professores, a partir deste momento, consolidam ações, atitudes, comportamentos e competências que serão conduzidos em períodos futuros.

As crenças pessoais e profissionais, originadas a partir do início da atuação docente, são perceptíveis e centradas no respeito e na valorização profissional, na preocupação com fatores relacionados à educação nacional, na valorização do ser humano e na busca de qualificação profissional, os quais podem compreender mecanismos e estratégias de sobrevivência no contexto escolar. Azevedo (2010) revela que as crenças são constituídas a partir das percepções que o professor apresenta do seu cotidiano, da sua prática pedagógica e do acúmulo do conhecimento acadêmico e profissional.

O fato de os professores estarem mais envolvidos com os acontecimentos escolares e a preocupação de buscarem diferentes estruturas para a melhoria da prática pedagógica 
geram determinadas expectativas que tendem a ser superadas nos ciclos subsequentes da carreira. Enquanto que as expectativas extrínsecas parecem apresentar linearidade na carreira docente, as expectativas intrínsecas, que se referem à individualidade e ao professor como pessoa, tornam-se relevantes no Ciclo de Consolidação das Competências Profissionais na Carreira.

A competência interpessoal, marcada pelo intercâmbio com os demais professores, tem início efetivo neste ciclo. Os professores já esboçam o trabalho em equipe, a cooperação e o diálogo como situações presentes na sua experiência profissional, evidenciado a noção de que a constituição de comunidades de práticas, enquanto espaços de aprendizagem, são aportes essenciais ao desenvolvimento profissional (CARDOSO; BATISTA; GRAÇA, 2014; WENGER; McDERMOTT; SNYDER, 2002). Além disso, frequentemente expressam criatividade, versatilidade, responsabilidade, dedicação e paciência como fatores pessoais presentes neste momento, o que assinala 0 domínio de metacompetências para a atuação profissional (BATISTA, 2008; CHEETHAM; CHIVERS, 1998; FARIAS et al., 2012; VAZ et al. 2017).

As fontes de conhecimento que promovem a atualização profissional docente estão centradas em leituras para orientação da prática pedagógica, na participação em eventos e a discussão com os pares. Diferentemente dos professores do Ciclo de Entrada na Carreira, que já possuíam formação continuada, os professores deste ciclo ainda buscam a participação em cursos de pós-graduação lato sensu.

\subsection{Ciclo de afirmação e diversificação na carreira}

O Ciclo de Afirmação e Diversificação na Carreira revela-se como um momento de confirmações das ações dos professores na sua prática pedagógica e da estabilização das competências na carreira docente. Em termos temporais, este ciclo compreendeu 17 professores de dez a 19 anos de atuação profissional, sendo considerado o maior ciclo em relação aos anos de docência.

O conhecimento tácito, originado a partir da associação entre as experiências vivenciadas ao longo da carreira, aliado ao conhecimento teórico adquirido por meio da formação inicial, dos cursos de pós-graduação e da participação em eventos, sublinha a atuação dos professores neste momento. 0 domínio do conhecimento sobre as rotinas básicas inerentes à profissão (como? quando? o quê?), bem como do conhecimento sobre o domínio de aspectos relacionados à profissão também é alcançado pelos professores no Ciclo de Afirmação e Diversificação na Carreira.

Identificou-se que grande parte dos professores investigados, a partir da experiência acumulada aolongo da carreira, passa aassumircargosadministrativos. Os cargos compreendem a direção e a vice-direção de escolas e as demais atividades de administração em secretarias municipais e estaduais de esportes. Todavia, a passagem por cargos administrativos exige do professor a aquisição de competências diferenciadas daquelas necessárias para ministrar aulas. Desta forma, alguns professores declaram de forma positiva essa experiência, enquanto que outros revelam aspectos preocupantes da face oculta da gestão administrativa.

O envolvimento nas discussões escolares e em mobilizações políticas proporciona a dimensão de expectativas voltadas à profissão. Além de emitirem expectativas profissionais e 
acreditarem na valorização da educação, os professores investigados anseiam a progressão funcional, melhorias salariais, na manutenção do plano de carreira, entre outros aspectos. De fato, os estudos que abordam os momentos centrais ou intermediários da carreira docente revelam que os professores se inserem em diferentes grupos, adquirem autoconfiança, mudam a sua trajetória, investem significativamente na profissão, estão mais motivados e dinâmicos para lançarem-se às experiências pessoais na profissão (GONÇALVES, 2000; 2009; HUBERMAN, 2000; NASCIMENTO; GRAÇA, 1998, STEFFY et al., 2000).

As metacompetências profissionais tornam-se proeminentes na carreira docente dos professores de Educação Física investigados (BATISTA; 2008; PAIVA; MELO, 2008). Os professores deste ciclo também conseguem rever a sua prática pedagógica declarando as estratégias que utilizam no seu cotidiano para a superação profissional e obtenção de competências. Há clareza quanto às suas estratégias de ação, o que é manifestado a partir da autopercepção de bons profissionais que possuem, revelando a motivação e o apreço pela carreira docente.

A inserção em cursos de pós-graduação constitui uma das alternativas utilizadas pelos professores para atualizarem-se na carreira. Entretanto, a partilha torna-se a fonte de conhecimento mais acentuada neste período. A participação em grupos de discussão com os pares, as trocas com os estudantes que medeiam as experiências e a intervenção pedagógica do processo de ensino e aprendizagem são também algumas maneiras indicadas pelos docentes. A participação em grupos de discussão eleva a criticidade e a capacidade de liderança, bem como estimula a mudança de trajetórias profissionais e o diálogo com as esferas administrativas para a concessão de propostas idealizadas para o contexto escolar. Além de partilhar o conhecimento com os professores da mesma área de formação, a troca de experiências com os demais colegas que compõem o corpo docente da escola se torna relevante, ao mesmo tempo em que as fontes documentais passam a constituir uma nova alternativa de atualização profissional.

\subsection{Ciclo de renovação na carreira}

Com o avanço na carreira, os professores modificam os seus comportamentos, crenças, perspectivas, expectativas, vontades e desejos em relação à sua atuação profissional. Os 26 professores investigados que pertencem ao Ciclo de Renovação na Carreira possuíam de 20 a 27 anos de docência, e relataram a necessidade de valorização da educação e da manutenção de conquistas trabalhistas para melhor garantia de renda salarial e da aposentadoria.

Ao analisar os professores deste ciclo percebe-se que a aposentaria representa tanto uma expectativa como perspectiva na carreira. Entretanto, a aposentadoria não surge no sentido de abandono, mas como uma etapa que está próxima, e que os professores pretendem alcançar. Investigações sobre a carreira docente revelam que este período pode ser caracterizado como um momento de desinvestimento amargo, marcado por dificuldades e afastamento afetivo (FOLLE et al., 2009; HUBERMAN, 2000;). Por outro lado, Hopf (2002) e Bragança (2004) descrevem que professores universitários em fase de aposentadoria manifestam ainda o desejo de permanência na profissão, buscam o engajamento em atividades docentes no viés de voluntário, além de manterem-se ativos nos seus propósitos e ideais profissionais. Fontoura, Doll e Oliveira (2015) descrevem que profissionais de distintas áreas, 
ao aposentarem-se, podem também experimentar sentimento de sofrimento, pelo afastamento da vida no trabalho, utilizando como mecanismo de reorganização pessoal a dedicação a outras atividades que não eram desempenhadas anteriormente.

Os professores do Ciclo de Renovação na Carreira podem ser caracterizados em três grupos que se entrelaçam neste momento da carreira docente em Educação Física. Além de professores ainda encantados com a docência, otimistas, entusiastas que procuram qualificar-se ingressando em cursos de mestrado e doutorado, na perspectiva da continuidade da formação, há os professores defensores da causa docente, em termos de valorização profissional (fatores políticos, econômicos e sociais) e da educação democrática, bem como os professores renovadores da atuação profissional, que a partir da experiência acumulada na realidade escolar, tanto no momento atual como no gozo da aposentadoria, perspectivam contribuir em outros níveis de ensino, publicar artigos científicos e a realizar consultorias no contexto educacional.

O domínio das atividades rotineiras, confirmado nos ciclos anteriores, aparece com mais clareza no Ciclo de Renovação na Carreira. Os professores questionam-se sobre a sua atuação, o papel da Educação Física na sociedade e a formação dos estudantes na escola. Diante da elevada bagagem profissional, a relação com os demais professores apresenta-se em relevo. Alguns estudos sobre a expertise, que descrevem as características de professores experientes na carreira, destacam este auxílio aos docentes mais jovens, pois os experts são conhecedores dos assuntos relacionados à profissão docente, sua experiência acumulada permite antecipar ações ainda não planejadas (BELL, 1997; BENHAM, 2002).

\subsection{Ciclo de maturidade na carreira}

- Ciclo de Maturidade na Carreira compreendeu 12 professores investigados, bem como os últimos anos de atuação docente (28 a 38 anos de docência), quando o conhecimento tácito é proeminente. 0 distanciamento da formação inicial faz com que os docentes justifiquem a sua prática mediante as vivências no contexto profissional. Isso se comprova por meio dos depoimentos dos professores, quando relatam que a experiência profissional orienta a sua prática pedagógica e auxiliou na construção do conhecimento para elaboração de suas aulas.

As expectativas e as perspectivas na carreira docente tendem a diminuir neste ciclo. Embora alguns docentes almejem o reconhecimento e a valorização profissional, outros ainda buscam oportunidades de qualificação, aguardam melhorias das condições de trabalho (locais, materiais e equipamentos) e que ensino público possa ser prioridade da educação nacional. Enquanto que a aquisição de conhecimentos em ciclos anteriores dava-se por diversos meios, neste momento as fontes documentais (leituras) compõem as principais alternativas de atualização profissional dos professores investigados.

Os docentes não consideram relevante o planejamento das estratégias pedagógicas, como mencionado em momentos anteriores da carreira. 0 que antes se apresentava como preponderante na atuação docente, agora passa a ser somente uma das orientações necessárias para o desenvolvimento de suas aulas. No entendimento de Batista (1998) e Graça e Batista (2013), a organização e a gestão constituem a competência que orienta as etapas do processo de ensino e aprendizagem e as dimensões de intervenção pedagógica, 0 que de determinado modo necessita ser contemplado em todos os ciclos da carreira docente. 
Ao final da trajetória docente, os professores investigados manifestam o sentimento de gratidão pelas conquistas ao longo da carreira. $O$ olhar para as suas experiências, as conquistas, o reconhecimento dos estudantes e da comunidade provoca um desejo de aposentadoria marcado pela realização profissional. Enquanto que o desejo da aposentadoria ocorre de maneira tranquila para alguns docentes, diante das considerações positivas sobre a trajetória profissional, as experiências negativas podem acelerar o desejo de aposentadoria e até de abandono da carreira, ocasionando constantes questionamentos, impaciência e distanciamento afetivo (GONÇALVES, 2000; 2009; HUBERMAN, 2000; NASCIMENTO; GRAÇA, 1998).

\section{CONCLUSÃO}

A sistematização das evidências encontradas possibilitou a identificação de cinco ciclos na trajetória profissional docente em Educação Física, bem como permitiu compreender como 0 professor de Educação Física evolui na carreira do magistério público municipal de Porto Alegre/ RS. A principal limitação do estudo compreende o número de professores investigados, e o aumento do número de participantes seria importante para proporcionar maior aprofundamento na análise dos dados que marcam e cruzam a trajetória docente em Educação Física.

A análise retrospectiva baseada na memória da vida profissional docente em Educação Física trouxe ao estudo a possibilidade de assinalar as mudanças de trajetória, os avanços e recuos ocorridos na carreira, o domínio de habilidades e a consolidação das estratégias pedagógicas para o ensino da Educação Física. Ressalta-se que a preocupação com a pósgraduação ficou evidente desde os anos iniciais da trajetória profissional docente em Educação Física.

O ciclo de Entrada na Carreira é caracterizado pela tomada de decisão, manifestada pelo desejo de permanecer na docência, bem como pelo choque com a realidade ocasionado por situações que promoveram desequilíbrio e a aquisição imediata de competências profissionais. Os ciclos posteriores são constituídos de maneira cíclica, ou seja, a transição de um momento da carreira para o outro sempre ocorre com a intersecção de conhecimentos e de competências profissionais.

Assim, o Ciclo de Consolidação das Competências Profissionais na Carreira foi considerado como um momento de transposição de conhecimentos que foram impulsionados e mantiveram-se presentes no decorrer da carreira. Considerado o maior em relação aos anos de docência, o Ciclo de Afirmação e Diversificação na Carreira pode ser entendido como um momento de experimentação e consolidação das experiências profissionais. O Ciclo de Renovação na Carreira desencadeou professores críticos, renovadores e ainda encantados pela docência. Diante das relações estabelecidas no âmbito da escola e pela particularidade e afinidade que os docentes expressam na atuação profissional, o Ciclo de Maturidade na Carreira em Educação Física é também considerado um momento ímpar no contexto educativo. De fato, os professores finalizam as suas atividades laborais ainda com expectativas positivas e sem a manifestação do sentimento de insucesso e abandono. Outra evidência, transversal aos vários ciclos da trajetória profissional, é que os professores vão reconfigurando o modo como exercem a função, bem como a sua identidade profissional.

Por fim, a operacionalização de estudos que possibilitem a ampliação dos ciclos na carreira docente, permitindo novos olhares para a descrição de cada ciclo da trajetória 
profissional docente de professores de Educação Física, constitui um desafio a ser enfrentado pelos demais pesquisadores da área.

\section{REFERÊNCIAS}

ANACLETO, Francis Natally de Almeida; CELY, Elisangela. In: SANTOS, José Henrique dos; ANACLETO, Francis Natally de Almeida; PEREIRA, Sissi Aparecida Martins. Desenvolvimento profissional de professores de Educação Física: reflexões sobre a formação e socialização docente. Curitiba: CRV, 2016. p. 137-163.

AZEVEDO. Edson Souza. Percepções dos professores de Educação Física sobre as orientações curriculares: estudo de caso dos Colégios de Aplicação no Sul do Brasil. 2010. 335f. Dissertação (Doutorado em Estudos da Criança) - Instituto da Criança, Universidade do Minho, Braga, 2010.

BARDIN, Laurence. Análise de Conteúdo. Lisboa: Edições 70, 2009.

BARONE, Thomas et al. A future for teacher education: developing a strong sense of professionalism. In: SIKULA, John P.; BUTTEY, Thomas J.; GUYTON, Edith (Orgs.). Handbook of research on teacher education. New York: Macmillan, 1996. p. 1118-1149.

BATISTA, Paula Maria Fazendeiro. Discurso sobre a competência: contributo para a (re) construção de um conceito de competência aplicável ao profissional do desporto. 2008. 591f. Dissertação (Doutorado em Ciências do Desporto) - Faculdade de Desporto, Universidade do Porto, Porto, 2008.

BELL, Martie. The development of expertise. Journal of Physical Education, Recreation and Dance, v. 8, n. 2, p. 34-38, Feb. 1997.

BENHAM, Robert $\mathrm{H}$. Expertise in sport instruction: Examining the pedagogical content knowledge of expert golf instructors. 2002. 197f. Doctoral thesis (Doctor of Philosophy) Department of Kinesiology, Michigan State University, Michigan, 2002.

BERSON, Michael J.; BREAULT, Rick A. The novice teacher. In: STEFFY, Betty E.; WOLFE, Michael. P.; PASCH, Suzanne. H.; ENZ, Billie. J. (Orgs.) Life cycle of the career teacher. California: Corwin Press, 2000. p. 26-43.

BOTH, Jorge. Bem-estar do trabalhador docente de educação física no início da carreira: síntese das investigações nacionais e internacionais. In: CONCEIÇÃO, Victor Julierme Santos; FRASSON, Jéssica Serafim (Orgs). Textos e contextos sobre o trabalho do professor de educação física no início da docência. Porto Alegre: Sulina, 2016. p. 85-109.

BRAGANÇA, Adriana Batista de Souza. Aposentadoria: a experiência de professores aposentados do Instituto de Biologia da UNICAMP. 2004. 102 f. Dissertação (Mestrado em Gerontologia) - Faculdade de Educação, Universidade Estadual de Campinas, Campinas, SP, 2004.

CARDOSO, Inês; BATISTA, Paula; GRAÇA, Amândio. Aprender a ser professor em comunidade de prática: um estudo com estudantes estagiários de Educação Física. In: BATISTA, Paula; GRAÇA, Amândio; QUEIRÓS. Paula. (Orgs.), 0 estágio profissional na (re)construção da identidade profissional em Educação Física. Porto: FADEUP, 2014. p.181-207. 
CHEETHAM, Graham; CHIVERS, Geoff. The reflective (and competent) practitioner: a model of professional competence which seeks to harmonize the reflective practitioner and competence-based approaches. Journal of European Industrial Training, v. 22, n. 6/7, p. 267-276, 1998.

CORSI, Adriana Maria. Dificuldades de professoras iniciantes e condições de trabalho nas escolas. In: LIMA, Emilia Freitas de. (Org.) Sobrevivências: no início da docência. Brasília: Líber Livro, 2006. p. 53-66.

CÔTÉ, Jean et al. Organizing and interpreting unstructured qualitative data. The Sport Psychologist v. 7, n. 2, p. 127-137, 1993.

DAGENAIS, Raymong. J.; STEFFY, Betty E.; ENZ, Billie J. The emeritus Teacher. In: STEFFY, Betty E. et al. (Orgs.). Life cycle of the career teacher. California: Corwin Press, 2000. p. 96103.

DÍAZ, Verónica Marín. El inicio de la vida profesional del docente universitario. Hacia la determinación de los elementos que marcan la socialización del profesor universitario principiante. Docencia e Investigación, v. 30, n. 5, p. 191-210, 2005.

FARIAS, Gelcemar Oliveira et al. Competências profissionais em Educação Física: uma abordagem ao longo da carreira docente. Motriz, v. 18 n. 4, p. 656-666, out./dez. 2012.

FARIAS, Gelcemar Oliveira et al. A identidade profissional de professores de educação física no início da carreira. In: CONCEIÇÃO, Victor Julierme Santos; FRASSON, Jéssica Serafim (Orgs). Textos e contextos sobre o trabalho do professor de educação física no início da docência. Porto Alegre: Sulina, 2016. p. 205- 225.

FEIMAN-NEMSER, Sharon. Staff development and learning to teach. In: ANNUAL MEETING OF THE EASTERN EDUCATION RESEARCH ASSOCIATION, 1982. Detroit. Anais... Detroit: AERA, 1982. p. 1-18.

FOLLE, Alexandra et al. Construção da Carreira Docente em Educação Física: Escolhas, Trajetórias e Perspectivas. Movimento, v. 15, n. 1, p. 25-49, jan./mar. 2009.

FOLLE, Alexandra; NASCIMENTO, Juarez Vieira do. Momentos marcantes da trajetória docente em Educação Física. Motriz, v. 15, n. 1, p. 92-103, jan./mar. 2009.

FONTOURA, Daniele dos Santos; DOLL, Johannes; OLIVEIRA, Saulo Neves de. O desafio de aposentar-seno mundo contemporâneo. Educação \& Realidade, Porto Alegre, v. 40, n. 1, p. 53-79, jan./mar. 2015.

FREIRE, Leila Inês Follmann; FERNANDEZ, Carmen. O professor universitário novato: tensões, dilemas e aprendizados no início da carreira docente. Ciência \& Educação, v. 21, n. 1, p. 255272, 2015.

FREITAS, Maria Nivalda de Carvalho. Organização escolar e socialização profissional de professores iniciantes. Cadernos de Pesquisa, n. 115, p. 155-172, mar. 2002.

GONÇALVES, José Alberto. A carreira das professoras do ensino primário. In: NÓVOA, Antônio. (Org.) A vida de professor. Porto: Porto Editora, 2000. p. 141-170.

GONÇALVES, José Alberto. Desenvolvimento profissional e carreira docente: fases da carreira, currículo e supervisão. Sísifo: Revista de Ciências da Educação, n. 8, p. 23-36, jan./abr. 2009. 
GRAÇA, Amândio; BATISTA, Paula. La educación física en las escuelas portuguesas según sus profesionales. Tándem: Didática de la Educación Física, Barcelona, v. 42, p. 37-47, 2013.

GRBICH, Carol. Qualitative Data Analysis: an introduction. 2. ed. SAGE, 2013.

HEBERT, Edward; WORTHY, Terry. Does the first year of teaching have to be a bad one? A case study of success. Teaching and Teacher Education, v. 17, p. 897-911, 2001.

HENRIQUE, José; COSTA, Bruno. A escolha profissional e a indução na carreira do professor de Educação Física. In: SANTOS, José Henrique dos; ANACLETO, Francis Natally de Almeida; PEREIRA, Sissi Aparecida Martins. Desenvolvimento profissional de professores de Educação Física: reflexões sobe a formação e socialização docente. Curitiba: CRV, 2016. p. 17-44.

HOPF, Ana Claudia Oliveira. Fico ou vou-me embora? Os sentimentos expressos por professores diante da aposentadoria. Revista da Educação Física/UEM, Maringá, v. 13, n. 2, p. 89-96, 2002.

HOPF, Ana Claudia Oliveira; CANFIELD, Marta de Salles. Profissão docente: estudo da trajetória de professores universitários de Educação Física. Kinesis, n. 24, p. 49-71, 2001.

HUBERMAN, Michel. O ciclo de vida profissional dos professores. In: NÓVOA, A. (Org.) Vida de professores. Porto: Porto Editora, 2000. p. 31-62.

ILHA, Franciele Roos da Silva; KRUG, Hugo Norberto. O professor iniciante e a educação física escolar: desafios que se somam. CONCEIÇÃO, Victor Julierme Santos; FRASSON, Jéssica Serafim (Orgs). Textos e contextos sobre o trabalho do professor de educação física no início da docência. Porto Alegre: Sulina, 2016. p. 181-204.

LENGERT, Rainer. 0 início da carreira docente: um estudo de representações sociais. 2005. 178 f. Dissertação (Mestrado em Teologia) - Escola Superior de Teologia, Instituto Ecumênico de Pós-Graduação em Teologia, São Leopoldo, 2005.

MONTEIRO, Filomena Maria de Arruda; MIZUKANI, Maria da Graça Nicoletti. Professoras das séries iniciais do ensino fundamental: percursos e processos de formação. In: REALI, Aline Maria de Medeiros Rodrigues; MIZUKAMI, Maria da Graça Nicoletti (Orgs.). Formação de professores: práticas pedagógicas e escola. São Carlos: EdUFSCar, 2002. p. 175-201.

NASCIMENTO, Juarez Vieira do; GRAÇA Amândio. A evolução da percepção de competência profissional de professores de Educação Física ao longo de sua carreira docente. In: CONGRESSO DE EDUCACÃO FÍSICA E CIÊNCIAS DO DEPORTE DOS PAISES DE LINGUA PORTUGUESA, 6.; CONGRESSO GALEGO DE EDUCACIÓN FÍSICA, 7. La Coruña, 1998. Actas... La Coruña: INEF Galícia, 1998. p. 320-335.

PAIVA, Kely César Martins de; MELO, Marlene Catarina de Oliveira Lopes. Competências, gestão de competências e profissões: perspectivas de pesquisas. Revista de Administração Contemporânea, v. 12, n. 2, p. 339-368, abr./jun. 2008.

RODRIGUES, Lia. Da Prática à Teoria: uma experiência em Educação Básica. 1987. 337 f. Tese (Doutorado em Educação) - Faculdad de Ciências de la Educación, Universidad Autônoma de Barcelona, Barcelona, 1987.

SANTOS, Núbia Zorzanelli dos; BRACHT, Valter; ALMEIDA, Felipe Quintão de. Vida de professores de Educação Física: o pessoal e o profissional no exercício da docência. 
SPARKES, Andrew C.; SMITH, Brett. Qualitative research methods in sport, exercise and health. New York: Routledge; 2014.

STEFFY, Betty E. et al. The models and its application. In: STEFFY, Betty E. et al. (Orgs.). Life cycle of the career teacher. California: Corwin Press, 2000. p. 1-23.

STROOT, Sandra. Organizational socialization: factors impacting beginning teachers. In: SILVERMAN, Stephen J.; ENNIS, Catherine D. (Orgs.). Student learning in Physical Education. Champaign: Human Kinetics, 1996. p. 339-365.

TARDIF, Maurice. Saberes profissionais dos professores e conhecimentos universitários: elementos para uma epistemologia prática profissional dos professores e suas consequências em relação a formação para o magistério. Revista Brasileira de Educação, v. 13, p. 5- 24, jan./ abr. 2000.

TARDIF, Maurice; RAYMOND, Danielle. Saberes, tempo e aprendizagem do trabalho no magistério. Revista Educação e Sociedade, v. 21, n. 73, p. 209-244, dez. 2000.

VALLE, lone Ribeiro. Carreira do magistério: uma escolha profissional deliberada? Revista Brasileira de Estudos Pedagógicos, v. 87, n. 216, p. 178-187, maio/ago. 2006.

VAZ, Jamille Machado et al. Percepção de competências profissionais de instrutores de atividades de aventura na natureza atuantes em Florianópolis/SC. Movimento, v. 23, n. 1, p. 295-310, jan./mar., 2017.

VEIGA, IIma Passos Alencastro et al. Docentes universitários aposentados: ativos ou inativos? Araraquara: Junqueira \& Marin, 2007.

WENGER, Etienne; McDERMOTT, Richard; SNYDER, William M. Cultivating Communities of Practice. Boston, Massachusetts: Harvard Business School , 2002. 
